\title{
LACK OF RECOMBINATION BETWEEN THE $X$ CHROMOSOMES OF DIFFERENT MEMBERS OF THE ANOPHELES GAMBIAE COMPLEX
}

\author{
C. F. CURTIS and J. CHALKLEY \\ Ross institute, London School of Hygiene and Tropical Medicine, London WCIE 7HT, U.K.
}

Received 1.xi.78

\section{INTRODUCTION}

Mosquitoes of the Anopheles gambiae complex are the principal vectors of malaria and filariasis in tropical Africa. The complex consists of six sibling species which produce sterile male hybrids when crossed (Davidson et al., 1967; White, 1974). The three sibling species to be considered were formerly referred to as species A, B and C but recently the names An. gambiae s.s., An. arabiensis and An. quadriannulatus have been proposed for them (Mattingly, 1977). Crosses between these species yield fertile female hybrids which makes it possible to carry out laboratory backcrossing experiments to elucidate the genetic nature of the hybrid male sterility (Curtis, 1978a, b). Coluzzi and Sabatini $(1967,1968)$ showed that the polytene autosomes of the three species are homo-sequential but the $\mathrm{X}$ chromosomes show many differences in banding pattern which can be largely explained by postulating a series of inversions during divergence of the species. In species hybrids the polytene chromosomes show some degree of asynapsis. This is very marked in the case of the two $\mathrm{X}$ chromosomes of females and much less apparent in the case of the autosomes. Extrapolation from the synapsis of polytene chromosomes to meiotic behaviour is of doubtful validity but one might expect that matings involving female hybrids would show close linkage of $\mathrm{X}$ chromosome factors but more nearly normal amounts of crossing-over between autosomal factors. This note describes tests of these expectations with regard to the $\mathrm{X}$ chromosome.

On the X chromosome only one morphological marker locus is available, since the sex-linked white eye and pink eye genes described by Mason (1967) were shown to be allelic by Curtis (1976). Thus only one of these genes could be used for this study. The linkage of white eye with the specific polytene chromosome characters of the sibling species is reported.

\section{Materials AND MEthods}

The following stocks have been used:

An. gambiae s.s. SOKw: derived from a stock which originated in Sokoto, Nigeria; carries sex-linked recessive white eye marker (Mason, 1967)

An. arabiensis KCD: from Kano, Nigeria; eye colour normal i.e. blackish brown.

An. quadriannulatus Chiredzi: from Chiredzi, Rhodesia (Zimbabwe), eye colour normal.

The insectary was maintained at $27^{\circ} \mathrm{C}$ and about 75 per cent relative 
humidity. The crosses were made in $20 \mathrm{~cm}$ cube cages where the stocks used were able to mate without assistance. Blood meals were provided on anaesthetised guinea-pigs and glucose solution was always available. The larvae were reared in water containing a piece of turf and were fed on finely ground "Farex" baby food. Virgin females for crossing were obtained by separating the sexes within 24 hours of emergence. Polytene chromosome preparations were made from ovarian nurse cells as described by Hunt (1973).

\section{Results AND Discussion}

In a female of An. gambiae s.s. the two polytene $\mathrm{X}$ chromosomes show complete synapsis, the pair being as thick as each of the synapsed pairs of autosomes. In the hybrids from gambiae $\times$ arabiensis or gambiae $\times$ quadriannulatus crosses the $\mathrm{X}$ chromosomes from each species can be identified by several features of the banding pattern: they lie partially or wholly unsynapsed and each one is thinner than the pairs of synapsed autosomes.

Fig. 1 shows the cross and backcross carried out with the SOKw (white eye) stock of An. gambiae s.s. and the $\mathrm{KCD}$ (wild type black eyed) stock of $A n$. arabiensis. On examination of the polytene chromosomes of the whiteeyed females from the backcross all showed two synapsed typical gambiae $\mathrm{X}$ chromosomes as in Plate $\mathrm{l}$ (i) and all the black-eyed females showed one typical gambiae and one typical arabiensis chromosome lying partially or wholly unsynapsed as in Plate l (ii) and (iii). There were no recombinants in which the white eye allele had been transferred to a predominantly arabiensis chromosome nor a wild type allele transferred to a predominantly gambiae chromosome among the 134 backcross progeny examined. Similarly

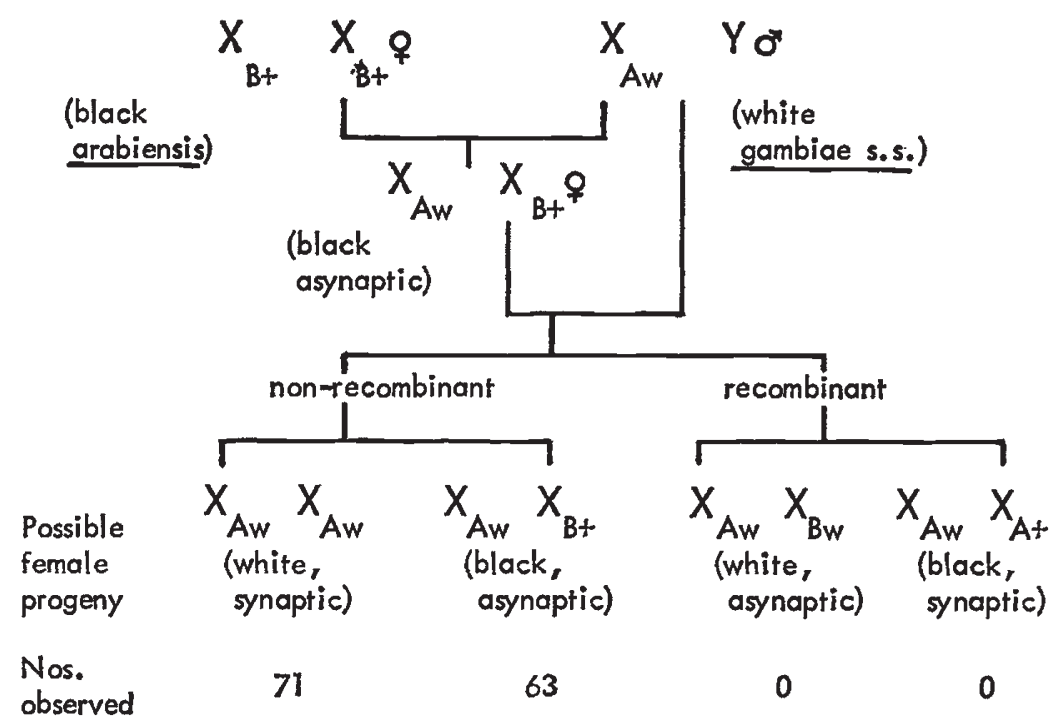

FIG. 1.-Cross between wild type An. arabiensis and white-eyed An. gambiae s.s. and backcross to the latter stock. The theoretically possible and actually observed types of backcross progeny are shown with respect to eye colour and polytene $\mathrm{X}$ chromosomes. $\mathrm{A}$ and $\mathrm{B}$ refer to $\mathrm{X}$ chromosomes of An. gambiae s.s. and An. arabiensis respectively and $w$ and + refer to the alleles at the sex-linked eye colour locus. 
no recombinants were found on examination of 17 backcross progeny derived from crossing SOK $\mathrm{w}$ to the Chiredzi stock of An. quadriannulatus and backcrossing to SOKw; all the black-eyed progeny showed two unsynapsed $\mathrm{X}$ chromosomes as in Plate 1 (iv).

The study could not be carried out with two markers of a conventional kind and the interpretation of the results is therefore not completely clear cut. However, it seems likely that the transfer, by crossing-over, of even a relatively small terminal segment of chromosome would have led in the backcross progeny to production of black-eyed females with some degree of synapsis between their polytene $\mathrm{X}$ chromosomes and, conversely, white-eyed females with some degree of asynapsis. Since no such individuals were found it seems likely that there is no pairing or crossing-over between the $\mathrm{X}$ chromosomes at meiosis in female hybrids. Therefore, it seems justifiable to rely on the white eye gene as a marker with which to follow the $\mathrm{X}$ chromosome of gambiae s.s. through species crosses and backcrosses. From backcrosses such as that illustrated in Fig. 1, sterility was found in all males whose black eyes indicated that their $\mathrm{X}$ chromosome originated from arabiensis. White eyes indicated that a male's $\mathrm{X}$ chromosome originated from gambiae and such males were mostly found to be fertile. In both types of male the $\mathrm{Y}$ chromosome and the majority of autosomal genes originate from gambiae. From these results it is concluded that interaction of the $\mathrm{X}$ chromosome of one species with the $\mathrm{Y}$ and/or autosomal factors of the other is a major factor in the causation of sterility in male hybrids from species crosses (Curtis, 1978a). More complicated crossing schemes, making use of the white eye marker, have been carried out to allow the production of sterile males with their autosomes very largely from one of the pure species and therefore likely to function as effective sterile males for control of wild populations of this species (Curtis, 1978a, $b$, and in prep.).

Another implication of the apparent lack of crossing-over between the $\mathrm{X}$ chromosomes of species hybrids is that these chromosomes are equivalent to the marked inversions available in Drosophila, Lucilia cuprina (Whitten et al., 1975) and Culex tritaeniorhynchus (Sakai and Baker, 1972, 1974), etc., which can be used for the selection of mutants, such as temperature sensitives, after mutagen treatment.

A study is now in progress of crossing-over between autosomal loci in species hybrids. The crosses involve insecticide resistance loci and a new recessive marker, colourless eye, which is phenotypically similar to white eye but differs in being autosomal. The two loci are analogous, and perhaps homologous, with those in An. stephensi reported by Aslamkhan (1973) and Sharma et al. (1977), who found white-eyed phenotypes due, respectively, to sex-linked and autosomal mutants. These authors designated their mutants, respectively, white eye and colourless eye and this terminology has been followed in the present case in the gambiae complex. In gambiae, colourless eye is associated with almost complete sterility in the female homozygote and the mutant is maintained by crossing heterozygous females to homozygous males. The marker is closely linked to the gene for dieldrin resistance both in individuals of pure arabiensis origin and in species hybrids and it is not yet clear whether the linkage is closer in the species hybrids.

Acknowledgments.-We are grateful to the Medical Research Council for financial support, to our colleagues in the Ross Institute insectaries for assistance of various kinds and to Drs G. Davidson and S. J. Miles for their comments on the manuscript. 


\section{REFERENCES}

aslamkhan, м. 1973. Sex chromosomes and sex determination in the malaria mosquito Anopheles stephensi. Pakistan 7. Zool., 5, 127-131.

Coluzzi, M., AND sabatini, A. 1967. Cytogenetic observations on species A and B of the Anopheles gambiae complex. Parassitologia, 9, 73-88.

Coluzzi, M., AND SABatini, A. 1968. Cytogenetic observations on species C of the Anopheles gambiae complex. Parassitologia, 10, 155-165.

CURTIs, c. F. 1976. Allelism test on two eye colour mutants in Anopheles gambiae species A (Abstract). Trans. Roy. Soc. trop. Med. E Hyg., 70, 281.

CURTIS, C. F. 1978a. Hybrid sterility in the Anopheles gambiae complex: mechanism and possible means of using it for genetic control (Abstract). Medical Entomology Centenary, Symposium Proceedings, Royal Society of Tropical Medicine and Hygiene, p. 133.

CURTIs, C. F. 1978b. Manipulation of the sterility system in sibling species crosses within the Anopheles gambiae complex (Abstract). Heredity, 40, 327-328.

DAvidsón, G., PATERSon, H. E., Coluzzi, M., MASON, G. F., AND Micks, D. w. 1967. The Anopheles gambiae complex. In Genetics of Insect Vectors of Disease, ed. J. W. Wright and R. Pal, pp. 211-250. Elsevier, Amsterdam.

HUNT, R. H. 1973. A cytological technique for the study of the Anopheles gambiae complex. Parassitologia, 15, 137-139.

mason, G. F. 1967. Genetic studies on mutations in species A and B of the Anopheles gambiae complex. Genet. Research, 10, 205-217.

mattingly, P. F. 1977. Names for the Anopheles gambiae complex. Mosquito Systematics, 9, 323-328.

SAKAI, R. K., AND BAKER, R. H. 1972. A method for the detection and measuring of concealed variability in the mosquito Culex tritaeniorhynchus. Genetics, 71, 287-296.

SAKAI, R. K., AND BAKER, R. H. 1974. Induction of heat sensitive lethals in Culex tritaeniorhynchus by ethyl methane sulfonate. Mosquito News, 34, 420-428.

SHARMA, v. P., MANI, T. R., ADAK, T., AND ANSARI, M. A. 1977. Colourless eye, a recessive autosomal mutant of Anopheles stephensi. Mosquito News, 37, 667-669.

write, G. B. 1974. The Anopheles gambiae complex and disease transmission in Africa. Trans. Roy. Soc. trop. Med. EO Hyg., 68, 279-298.

WhitTen, M. J., FOSTER, G. G., ARNold, J. T., AND konovalov, c. 1975. The genetics of the Australian Sheep Blowfly, Lucilia cuprina. In Handbook of Genetics, ed. R. C. King. Plenum, New York. 

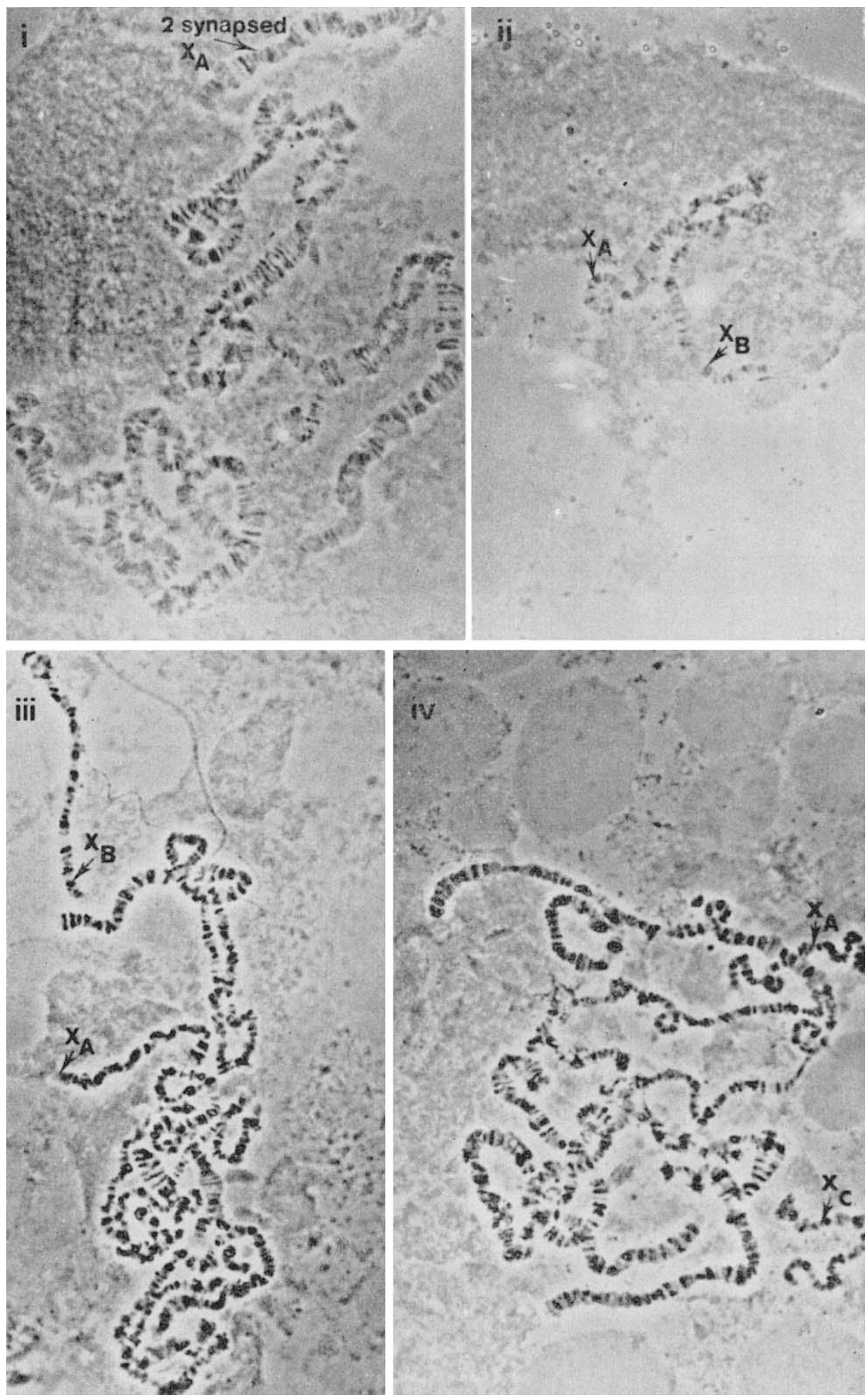

Plate 1.-Polytene chromosomes from ovarian nurse cells of backcross progeny: (i) whiteeyed female derived from the backcross shown in fig. 1, note synapsed gambiae s.s. X chromosomes; (ii) and (iii) black-eyed females derived from the backcross shown in fig. 1, note two partly or wholly unsynapsed $\mathrm{X}$ chromosomes, one derived from each species; (iv) black-eyed female derived from gambiae s.s. $\times$ quadriannulatus cross followed by a backcross as in fig. 1 , note two unsynapsed $\mathrm{X}$ chromosomes, one derived from each species; Note: $\mathrm{X}_{\mathrm{A}}, \mathrm{X}_{\mathrm{B}}$ and $\mathrm{X}_{\mathrm{C}}$ refer to $\mathrm{X}$ chromosomes derived from gambiae s.s., arabiensis and quadriannulatus respectively. 